\title{
Consequences of Drug Abuse among Female and Male Population of Karachi: A Statistical Surveyed Approach
}

\author{
Rana Saba Sultan ${ }^{1, *}$, Jawed Aziz Masudi ${ }^{1}$, Afaq Ahmed Siddiqui ${ }^{2}$ and Najia Mansoor ${ }^{3}$ \\ ${ }^{1}$ Department of Sociology, Faculty of Social Sciences, University of Karachi, Pakistan \\ ${ }^{2}$ Department of Pharmaceutical Chemistry, Faculty of Pharmacy, University of Karachi, Pakistan \\ ${ }^{3}$ Department of Pharmacology, Faculty of Pharmacy, University of Karachi, Pakistan
}

\begin{abstract}
Drugs are chemicals. Different drugs, because of their chemical structures, can affect the body in different ways. The most obvious effects of drug abuse which are manifested in the individuals include ill health, sickness and ultimately, death. The social life is also not spared by the hazardous impacts of the problem. Whereas the load at health department is increased, rise in crime rate is also a perilous effect faced by the society related to the growth of abusers in the country. The following study highlights the different effects that can influence male and female drug abusers to get rid of their drug misuse habits. Abusers age, level of awareness about drugs adverse effects, their encounters to health ailments including the life threatening infection HIV, and involvement in crimes were included in the survey which was carried out in Karachi in order to assess the magnitude of this problem.
\end{abstract}

Keywords: Drug misuse, drug abuse, dopamine, euphoria, HIV, hallucination, addiction, drug-drug interactions.

\section{INTRODUCTION}

In a fast growing world of competitions and challenges, the accompanying mental stress has given rise to the escaping ways, one of these being misuse and abuse of both prescription and illicit drugs .The drug abuse refers to the use of a medication without a prescription, in a way other than as prescribed, or to get a pleasant or euphoric feeling especially at higher doses than prescribed (Abadinsky, 2010). While the term drug misuse denotes the misuse is trying to treat a condition or symptom without aiming to get any euphoric effect, but not according to the directions of a health care provider. The FDA stresses that both of these conditions can be harmful and even life threatening to the individuals. This is globally an alarmingly worrisome problem as according to the studies 15 percent of United States high school students are involved in the misuse of prescription controlled drugs (National Center on Addiction and Substance Abuse, 2011).

According to another study the number of emergency department visits due to misuse or abuse of prescription drugs has risen $98.4 \%$ since 2004 in the United States. 1.2 million emergency department visits were related to misuse or abuse of prescription drugs, compared with 1 million visits related to use of illicit drugs such as heroin and cocaine (CDC, 2011). In 2009, Different drugs produce different effects in fact

*Address correspondence to this author at the Department of Sociology, University of Karachi, Pakistan; E-mail: criminologist_jmasudi@yahoo.com some of them can cause such changes in body physiology that last long after the person has stopped taking drugs, maybe even permanently. The method of the drug entering the body impacts on how the drug affects the person.

Most abused drugs directly or indirectly target the brain's reward system by flooding the circuit with dopamine, a neurotransmitter brain that regulate movement, emotion, cognition, motivation, and feelings of pleasure. When drugs enter the brain, they can actually change how the brain performs its jobs. These changes are what lead to Paranoia, Aggressiveness, Hallucinations, Impaired Judgment Impulsiveness, Loss of Self-Control and compulsive drug use, the hallmark of addiction (Babbie, 2010).

Usually abusers use prescription drugs to help them deal with problems, manage their lives, in modern world misuse of technology has also opened the doors to miseries of life as $88 \%$ of the over 10,700 Internet sites reviewed by National Association of Boards of Pharmacy (NABP) do not require a valid prescription. People who become addicted to prescription drugs may also found engaged in moving from doctor to doctor $t$ to obtain multiple prescriptions for the drug(s) they abuse.

The negative consequences of drug abuse affect not only individuals who abuse drugs but also their families and friends, various businesses, and government resources. III health, sickness and particularly devastating the contraction of needle borne illnesses including hepatitis and HIV/AIDS through 
injection drug use are the ones faced by the abusers (Liu, et al. 2006 and Nelson, et al., 2011). Centers for Disease Control and Prevention (CDC) reports that 123,235 adults living with AIDS in the United States in 2003 contracted the disease from injection drug use, and the survival rate for those persons is less than that for persons who contract AIDS from any other mode of transmission. Besides their effects on individuals' life, drug abuse by the citizens also puts burdens on societies. Children of individuals who abuse drugs often are abused or neglected as a result of the individuals' preoccupation with drugs. National-level studies have shown that parents who abuse drugs often put their need to obtain and abuse drugs before the health and welfare of their children. National Survey on Drug Use and Health (NSDUH) data collected during 2002 and 2003 indicate that 4.3 percent of pregnant women aged 15 to 44 report having used illicit drugs in the past month. Moreover, that same data show that 8.5 percent of new mothers report having used illicit drugs in the past month. Children whose parents and other family members abuse drugs often are physically or emotionally abused and often lack proper immunizations, medical care, dental care, and necessities such as food, water and shelter.

The risk to children is even greater when their parents or guardians manufacture illicit drugs such as methamphetamine. Children commonly suffer from neglect that leads to psychological and developmental problems. The economic impact of drug abuse on businesses whose employees abuse drugs can be significant. While many drug abusers are unable to attain or hold full-time employment, those who do work put others at risk, particularly when employed in positions where even a minor degree of impairment could be catastrophic; airline pilots, air traffic controllers, train operators, and bus drivers are just a few examples. Economically, businesses often are affected because employees who abuse drugs sometimes steal cash or supplies, equipment, and products that can be sold to get money to buy drugs. Moreover, absenteeism, lost productivity, and increased use of medical and benefits by employees who abuse drugs affect a business financially (Chaloupka, et al. 2009).

The economic consequences of drug abuse severely burden federal, state, and local government resources. This effect includes extensive medical treatment for repeatedly encountered health ailments; abuse, neglect, and abandoning of their children, some also commit a host of other crimes including domestic violence, assault, burglary, and identity theft (Deschenes, et al. 1991). Moreover, the time and manpower involved in investigating and cleaning up increase the workload of an already overburdened law enforcement system (National Drug Intelligence Center, 2006).

In Pakistan, little attention has been paid to the issue of drug abuse on the basis of gender Although the findings of various surveys postulate a very limited number of women with drug dependency problems, this assumption is open to question as official surveys and reports have never endeavored to represent women adequately. While it may be true that the number of female drug users is much lower than that of male drug users, it must be remembered that in Pakistani society, cultural constraints often lead to the concealment of problems related to women, including drug abuse, and this can cause difficulties in identification of drug abuse by health professionals and researchers.

\section{MATERIAL AND METHODS}

\section{Material}

The cosmopolitan city of Karachi was the universe for this study. Here male and female are socially interactive and easily accessible on different occasion. It is densely populated and medley of various multiethnic and multi-lingual cultures of the urban areas in the city. So it was guessed that a comprehensive survey sample may be obtained.

In this research, male and female drug users were taken as the sample. Data of male and female drug users collectively they are 1000 in number; it was really appropriate strength of the addicts to conduct this survey. 700 addicts attempted the questionnaires, but after the correction of data and viewing it 200 interviews were deleted from the questionnaires, so the remaining 500 addicts were analyzed and became the part of service sample. In this survey addicts were chosen on the direct request from the researcher or through reference or recommended by the important informants and through referral. Addicts were the in habitants of the posh and sub urban areas and have been interviewed during the survey.

\section{Method}

\section{Sampling Technique}

The researcher has utilized the sampling technique or tactics of "non-probability sampling". In this 
technique, the elements have selected on individual judgment and assessment is the kernel in the selection. Due to ignorance of population size the "Snowball Sampling" is utilized. According to Babbie (2010) "snowball sampling" is a process of gathering new faces through a method of onward referral from familiar cases: begins with familiar persons fulfilling the criteria; nominations; or nominees are communicated and interviewed.

\section{Collection of Data}

In this study the data were collected on the basis of the "interview schedule" containing the addicts with salient features, demographic characteristics of the respondents, their drug usage history, their pattern and practice of drug usage, their knowledge attitude and practice about drug use, rehabilitation, and consequences/impacts of drug usage. Frankfort (1994) argue that "this is the best form, produced for information clearly in all respects, accuracy adopted in wordings, their sequence have been assigned a proper order and adhering similarity for each of the addicts. The aim was only to ensure that disparity between responses may be attributed due to the real differences between the addicts and not to fluctuations in the interview. The researcher endeavors to avoid any risk that may differ in the wording of questions, such as, might elicit differences in responses.

Prior to adopt the interview schedule, pretesting method has been introduced in order to delete any kind of errors and complications from the interview schedule.

\section{Statistical Approach}

The collected data was processed by coding; editing, tabulating, recoding, re-tabulating and transformed the simple tables by adjusting into contingency tables in view of the hypotheses for testing the different hypothesis of causes of drug abuses.

The contingency tables aim to investigate the verification of the two variables (Thakur; 1993).

\section{Statistical Method of Data Analysis}

According to Sarantakos (1998) "the most critical occasion research design is in fact the analysis and explanation of data. The penal of the social scientists focus earnestly towards their analysis and explanation on collection of the data, Explanation is a process including a number of operations which are interrelated. During a satirical induction nothing is justified in perfect sense. Even it may not be ascertain with all conviction about the universe, that is true or not from which the data has been drawn. After all through a critical method one may approached easily that anything is not correct about the universe or in alternative that something is true. The hypothesis finally undergoes either acceptance or rejection after qualifying these tests. The utilization of a proper method renders on the quality of data.

In the present study the application of chi-square was used for confirming the linkage between variables.

\section{Chi-Square}

According to Kothari (2004) "Chi-square is a measure for the judgment that weather observed frequency of an event is compatible with theoretical frequency expected on the basis of assumed distribution. So we establish level of significant what point the hypothetical universe of no charge will be rejected. The value of Chi-square can be calculated by using the formula mentioned below:

Chi-square $=\sum(\mathrm{fo}-\mathrm{fe})^{2} / \mathrm{fe}$

Where: fo is the actual frequency and fe is the expected frequency.

\section{Degree of Freedom}

Sarantakos (1998) argue that "in order to compute the value of chi-square from a contingency table, the number of Degree of freedom must also be known before the table is used, as it gives the proper reference of row of the table of critical values.

Degree of freedom $=$ (number of columns- 1 ) (number of rows-1)

\section{Level of Significance}

According to Healey (2009) "the significance level indicates the risk of rejecting Ho when it should have been accepted, which we are prepared to take. The value most commonly used by social researchers is 0.05 , which means that there is a 5 percent probability of rejecting a true Ho. In this study, has applied the value of chi-square for 0.05 level of significance.

\section{ANALYSIS AND RESULT}

In this study, six hypotheses related to the consequences of drug abuse were tested. Out of six 
Table 1: Result of Six Hypotheses Related to the Consequences of Drug Abuse with Chi-Square Value, p-Value and Conclusion

\begin{tabular}{|c|c|c|c|c|}
\hline S. No. & Hypotheses & $\begin{array}{l}\text { Chi-Square } \\
\text { Values }\end{array}$ & p-values & $\begin{array}{l}\text { Empirical } \\
\text { Conclusions }\end{array}$ \\
\hline $\mathrm{H}_{10}$ & $\begin{array}{l}\text { Age of drug users of drug user is not likely to be related with their } \\
\text { desire to get rid of drug usage. }\end{array}$ & 3.272 & 0.916 & Accepted \\
\hline $\mathrm{H}_{20}$ & $\begin{array}{l}\text { Level of education of drug user is not likely to be related with their } \\
\text { awareness regarding the will of rehabilitation. }\end{array}$ & 10.318 & 0.413 & Accepted \\
\hline $\mathrm{H}_{30}$ & $\begin{array}{l}\text { Frequency of drug abuse is not likely to be related with their } \\
\text { sufferings from disease. }\end{array}$ & .468 & 0.494 & Accepted \\
\hline $\mathrm{H}_{40}$ & $\begin{array}{c}\text { Frequency of drug usage is not likely to be related with } \\
\text { involvement in crimes. }\end{array}$ & 1.183 & 0.277 & Accepted \\
\hline $\mathrm{H}_{50}$ & $\begin{array}{l}\text { Frequency of drug usage is not likely to be related with the positive } \\
\text { HIV/AIDS. }\end{array}$ & .850 & 0.974 & Accepted \\
\hline $\mathrm{H}_{60}$ & $\begin{array}{l}\text { Occupation of drug user is not likely to be related with weather } \\
\text { they have ever been arrested for drug usage. }\end{array}$ & 11.706 & 0.020 & Rejected \\
\hline
\end{tabular}

hypotheses five were accepted and one hypothesis is rejected. The hypothesis, Chi-square value, $p$-value and conclusion are given in the following Table 1.

Chi-Square test is used to find the association between two categorical variables. If the $p$-value of chisquare is less than 0.05 then we reject the $\mathrm{H}_{\mathrm{O}}$ and accept $\mathrm{H}_{\mathrm{A}}$.

In hypotheses-1, we have two variables age and get rid of drug usage and found that the p-value of chisquare testis not less than 0.05 . It means we accept the null hypothesis and conclude that there is no significant relationship between ages and get rid of drug usage of respondents.

In hypotheses-2, we have two variables education level and awareness about the negative effects of drug abuse and found that the p-value of chi-square test is not less than 0.05 . It means we accept the null hypothesis and conclude that there is no significant association between education level and awareness about the negative effects of drug abuse of respondents.

In hypotheses-3, we have two variables frequency of drug use and suffered from any disease due to drug use and found that the p-value of chi-square test is greater than 0.05 . It means we accept the null hypothesis and conclude that there is no significant association between frequencies of drug use and suffered from any disease due to drug use of respondents.

In hypotheses-4, we have two variables frequency of drug use and ever arrested for drug use and found that the $p$-value of chi-square test is not less than 0.05 . It means we accept the null hypothesis and conclude that there is no significant relationship between frequency of drug use and ever arrested for drug use of respondents.

In hypotheses-5, we have two variables frequency of drug use and type of disease and found that the $p$ value of chi-square test is not less than 0.05 . It means we accept the null hypothesis and conclude that there is no significant relationship between frequency of drug use and type of disease of respondents.

In hypotheses-6, we have two variables occupation and ever arrested for drug use and cause for taking drug and found that the $p$-value of chi-square test is less than $0.05(p<0.05)$. It means we reject the null hypothesis and conclude that there is a significant relationship between occupations and ever arrested for drug use of respondents.

\section{DISCUSSION}

Drug abusers are usually considered to be an unbalanced debt to the society. In Pakistan, they have become a great burden on its already overloaded health and legal system and in order to overcome this problem a strong need to investigate the consequences of this social dilemma is felt.

It is a significant finding of the study that 84 percent of the respondents claimed to have been unaware of any negative effects arising from drug abuse prior to their initial use of drugs. Forty-six percent were not aware that addiction treatment services were available should they wish to seek help for their addiction. The 
study implies that the age and level of education of abusers does not affect their will (UNDCP, 2000).

According to our study Frequency of drug abuse is not likely to be related with their sufferings from disease. HIV, Hepatitis, TB, STI and other disease were found in respondent after using drug. But majority are suffering from HIV. Overall $70 \%$ of respondents confirm that they are suffering from HIV while using drugs.

Occupation of drug user is likely to be related with whether they have ever been arrested for drug usage. Only few unemployed abusers were ever arrested for being a drug abuser while none of the private employees fell in this category.

\section{CONCLUSION}

Age of drug users is not likely to be related with their desire to get rid of drug usage. Although all drug users want to get rid of their abuse, most of the users fall in age group of 21 to 34. Level of education of drug user is also not related with awareness regarding the will of rehabilitation. We observed that either the person is aware or not regarding negative effects of drug abuse their education level is illiterate, literate and primary. Very few respondents have more than primary education. Majority of the respondents are aware about the negative effects of drug abuse. Frequency of drug abuse is not likely to be related with their sufferings from disease. All respondents use the drug on daily basis either the person suffered from any disease due to drug use or not. Frequency of drug usage is also not likely to be related with sufferings from disease and also not related with involvement in crimes. All respondents use the drug on daily basis either the person ever arrested for drug use or not. Frequency of drug usage is also not likely to be related with the HIV positive. Majority of the respondents have HIV positive either they are daily user or weekly user. Occupation of drug user is likely to be related with weather they have ever been arrested for drug usage.

\section{REFERENCES}

Abadinsky, H., 2010, Drug Use and Abuse: A Comprehensive Introduction, Cengage Learning.

Babbie, E., 2010, The Basics of Social Research, Cengage Learning.

CDC, "Overdoses of Prescription Opioid Pain Relievers - United States, 1999-2008," in Vital Signs, November 4, 2011.

Chaloupka, F.J., Grossman, M., Bickel, W.K., Saffer, H., 2009, The Economic Analysis of Substance Use and Abuse: An Integration of Econometric and Behavioral Economic Research. National Bureau of Economic Research Conference Report, University of Chicago Press.

Deschenes, E.P., Anglin, M.D., and Speckart, G. Narcotics addiction: Related criminal careers, social and economic costs. Journal of Substance Abuse. 1991; 7: 383-411.

Frankfort Nachmias, chavaNachmias, 1994, Research methodology in the social sciences, London, St. Martin Press.

Healey, J. , 2009, The Essentials of Statistics: A Tool for Social Research, Cengage Learning.

Kothari, C. R., 2004, Research Methodology: Methods and Techniques, New Age International.

Liu, H., Grusky, O., Li, X., and Ma, E. Drug users: a potentially important bridge population in the transmission of sexually transmitted diseases, including AIDS, in China. Sexually Transmitted Diseases 2006; 33: 111-117. http://dx.doi.org/10.1097/01.olq.0000199762.28231.ee

National Center on Addiction and Substance Abuse, "Adolescent Substance Use: America's \#1 Public Health Problem," (June 2011) at Columbia University.

National Drug Intelligence Center, 2006,National Drug Threat Assessment, USA.

Nelson, P.K., Mathers, B.M., Cowie, B., Hagan, H., Des Jarlais, D., Horyniak, D., and Degenhardt, L. Global epidemiology of hepatitis $B$ and hepatitis $C$ in people who inject drugs: results of systematic reviews. Lancet.2011; 378: 571-583. http://dx.doi.org/10.1016/S0140-6736(11)61097-0

Sarantakos S., 1998, Social research, New York, Mcmillan press.

Thakur D., 1993, Research methodology, New Delhi, Deep and Deep publication.

\section{DOI: http://dx.doi.org/10.6000/1929-4409.2015.04.07}

(C) 2015 Sultan et al.; Licensee Lifescience Global.

This is an open access article licensed under the terms of the Creative Commons Attribution Non-Commercial License (http://creativecommons.org/licenses/by-nc/3.0/) which permits unrestricted, non-commercial use, distribution and reproduction in any medium, provided the work is properly cited. 